\title{
MANIPULATION OF ROOT HAIR DEVELOPMENT AND SORGOLEONE PRODUCTION IN SORGHUM SEEDLINGS
}

\author{
XIAOHAN YANG, ${ }^{1, *}$ THOMAS G. OWENS, ${ }^{2}$ BRIAN E. SCHEFFLER,, 3 \\ and LESLIE A. WESTON ${ }^{1}$
}

${ }^{1}$ Department of Horticulture, Cornell University, Ithaca, New York 14853, USA

${ }^{2}$ Department of Plant Biology, Cornell University, Ithaca, New York 14853, USA

${ }^{3}$ USDA/ARS, National Center for Natural Products Research

Oxford, Mississippi 38677, USA

${ }^{4}$ USDA-ARS-CGRU, MSA Genomics Laboratory, 141 Experiment Station Rd., Stoneville, MS 38776, USA

(Received August 7, 2002; accepted September 8, 2003)

\begin{abstract}
Sorghum (Sorghum bicolor) roots exude a potent bioherbicidesorgoleone. Previous work indicates that sorgoleone is produced in living root hairs. We have developed a mist system that resulted in abundant production of root hairs exuding sorgoleone and a mat system that significantly inhibited root hair development and consequently sorgoleone production. Applying $\mathrm{Ag}^{+}$(an ethylene action inhibitor) at $1.2 \mathrm{mM}$ to the seedlings grown in the mist system also inhibited root hair formation and elongation. Hypoxic conditions in the mist system did not result in the inhibition of root hair growth as compared to the standard air atmosphere $\left(20.8 \% \mathrm{O}_{2}\right)$. Applying ethephon (an ethylene-releasing agent) at $0.031 \mathrm{mM}$ to the roots of seedlings grown in the mat system with water running at $1 \mathrm{ml} / \mathrm{min}$ reversed the inhibition of root hair development by water movement. These results indicate that either water movement or ethylene can be utilized to manipulate root hair development and sorgoleone production in sorghum seedlings. It is hypothesized that water movement reduced the local ethylene concentration on the root surface and consequently inhibited root hair development of sorghum seedlings grown in the mat system.
\end{abstract}

Key Words-Root hair, Sorghum bicolor, sorgoleone, ethylene, oxygen, ethephon, silver thiosulphate, allelopathy, hypoxic condition.

*To whom correspondence should be addressed. E-mail: xy16@cornell.edu 


\section{INTRODUCTION}

Allelopathy offers great potential for alternative weed control through the release of allelochemicals toxic to competing vegetation. Various researchers have proposed genetically engineering allelochemical production into plants for the development of transgenic crops that produce their own defense against weeds (Gressel, 2000; Duke et al., 2001). Certain plant species possess a potent weed-suppressing ability, e.g., sorghum [Sorghum bicolor (L.) Moench], winter rye (Secale cereale L.), winter wheat (Triticum aestivum L.), and others (Weston, 1996). Sorghum roots exude biologically-active hydrophobic substances, one major component of which is known as sorgoleone, characterized as 2-hydroxy-5-methoxy-3-[(8' $\left.Z, 11^{\prime} Z\right)-8^{\prime}$, $11^{\prime}, 14^{\prime}$-pentadecatriene]- $p$-benzoquinone (Chang et al., 1986; Netzly and Butler, 1986; Nimbal et al., 1996). Sorgoleone is toxic to both small-seeded broadleaf and grass weeds at concentrations as low as $10 \mu \mathrm{M}$ in root uptake studies (Einhellig and Souza, 1992; Nimbal et al., 1996). It is an inhibitor of both photosynthetic (Einhellig et al., 1993; Gonzalez et al., 1997; Rimando et al., 1998) and mitochondrial electron transport (Rasmussen et al., 1992; Einhellig, 1995; Czarnota, 2001). In addition, Meazza et al. (2002) reported that sorgoleone strongly inhibited hydroxyphenylpyruvate dioxygenase (HPPD) at concentrations lower than that of juglone, a napthaquinone produced by black walnut (Juglans nigra L.). HPPD is the novel target site for a new family of triketone herbicides. Inhibition of this enzyme disrupts the biosynthesis of carotenoids and results in foliar bleaching (loss of chlorophyll), which is also observed in sorgoleone-treated seedlings (Nimbal et al., 1996).

Recent work in our laboratory suggested that sorgoleone is produced only in living root hairs (Czarnota et al., 2001). Root hairs are tubular extensions of epidermal cells that have their origin either in any protoderm cells or in specialized protoderm cells called trichoblasts (Cormack, 1949; Row and Reeder, 1957; Ridge, 1995; Peterson and Farquhar, 1996; Pemberton et al., 2001; Ryan et al., 2001). Root hairs contribute as much as $77 \%$ to the total root surface area of cultivated crops, forming the major point of contact between the plant and the rhizosphere. (Parker et al., 2000). Root hairs play important roles in plant life processes, including uptake of water and nutrients, production of substances that mediate plant-microbial associations, regulation of plant growth, and determination of microbial community structure in the plant rhizosphere (Fan et al., 2001; Grierson et al., 2001; Michael, 2001; Inderjit and Weston, 2003).

Normal root hair development encompasses four events: hair initiation, swelling, transition to tip growth, and tip growth (Parker et al., 2000). Root hair development is either favored or restricted by certain physiological factors. Increasing the temperature of the rhizosphere, especially above the optimum for the plant, often leads to enhanced root hair development and shorter, thicker roots. However, the influence of aeration on root hairs is unclear (Michael, 2001). When a growing root meets a physical obstruction, root hair formation is increased (Roberts, 1993; 
Michael, 2001). Dark-grown wild-type Arabidopsis seedlings, which produce little ethylene, are largely hairless. However, exogenous treatment of dark-grown Arabidopsis plants with either ethylene or 1-aminocyclopropane-1-carboxylic acid restores the development of root hairs in cells overlying the anticlinal cortical cell walls (Cao et al., 1999). Genes involved in ethylene signal transduction influence root hair elongation. Mutations in ethylene receptor 1 (ETR1) and EIN2 (which encodes for a metal transporter protein for ethylene signal transduction) inhibit root hair elongation. Mutations in constitutive triple response 1 (CTRl), the negative regulator of ethylene signaling, promote root hair elongation. Therefore, it is hypothesized that ethylene plays an important role in root hair initiation and elongation (Dolan, 2001).

Ethylene is a potent inhibitor of cortical cell division, an effect that can be counteracted by applying silver ions $\left(\mathrm{Ag}^{+}\right)$, which block the ethylene signal transduction pathway (Heidstra et al., 1997; Pereira-Netto, 2001). The rhizosphere environment influences ethylene production within the roots and gas exchange at the root surface. If gas exchange is enhanced, the removal of ethylene will be accelerated, thereby limiting its function in hair formation (Michael, 2001). The final step in the ethylene biosynthetic pathway (the conversion of ACC to ethylene) requires molecular oxygen, as shown in Arabidopsis silique tissue grown under subambient oxygen $(2.5$ or $5.5 \%)$ conditions where no subsequent ethylene was detected (Ramonell et al., 2002).

In this study, we attempted to manipulate root hair development and sorgoleone production in sorghum seedlings by physiological regulation of ethylene production or action for the purpose of establishing a basis for analysis of gene expression associated with sorgoleone production in sorghum root hairs. Specifically, the effects of hypoxic conditions, $\mathrm{Ag}^{+}$(an inhibitor of ethylene action), ethephon (an ethylene releasing agent), and movement of air/water surrounding developing roots on root hair formation in sorghum $(S$. bicolor $\times S$. sudanense $)$ SX17 were examined.

\section{METHODS AND MATERIALS}

Plant Material and Growth Conditions. Sorghum (S. bicolor $\times$ S. sudanense $)$ SX17 seeds (Monsanto Company, St. Louis, MO) were utilized in all laboratory studies. Seed was rinsed three times in tap water and surface sterilized with $15 \%$ $(\mathrm{v} / \mathrm{v})$ bleach $\left(\mathrm{CLOROX}^{\circledR}\right)$ containing $5.25 \%$ sodium hypochlorite for $10 \mathrm{~min}$. After three washes in purified water (RiOs 16 system, Millipore Corporation, Bedford, $\mathrm{MA})$, seed was germinated for $60 \mathrm{hr}$ at room temperature $\left(24 \pm 1^{\circ} \mathrm{C}\right)$ in the dark using two different growth systems:

1. The mat growth system is described in Figure $1 \mathrm{~A}$. A glass plate $(20 \times 50$ $\mathrm{cm} ; 0.4 \mathrm{~cm}$ thick) was slanted at approximately $4^{\circ}$. Two layers of cheese cloth $(20 \times 20 \mathrm{~cm})$ were spread over the glass plate, and 200 seeds were 


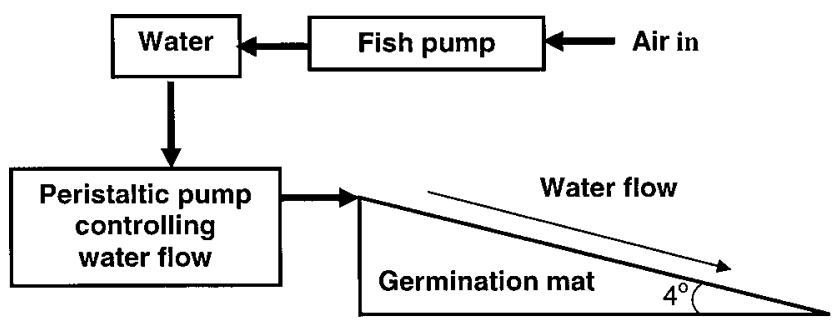

(A)

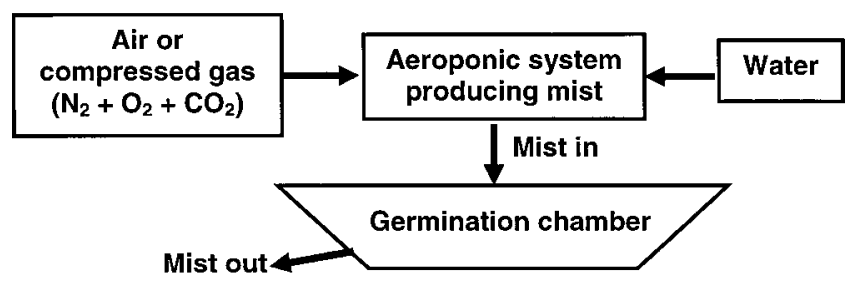

(B)

FIG. 1. Diagram of two systems for regulating root hair development in sorghum seedlings. (A) The mat system. The germination mat consists of a glass plate sloping $4^{\circ}$, two layers of cheese cloth over the plate, 200 seeds on the cheese cloth, a layer of clear polyethylene covering the seeds, a glass plate over the plastic sheet. Water was applied to the cheese cloth. (B) The mist system. Seeds were germinated inside a black plastic germination chamber under flowing moist mist supplied by the aeroponic system.

spread evenly on the cheese cloth. A layer of clear 2-mil polyethylene sheeting (Lab Safety Supply Inc., Janesville, WI) was used to cover the seeds. Finally, a matching glass plate $(20 \times 50 \mathrm{~cm} ; 0.4 \mathrm{~cm}$ thick $)$ was placed on top of the plastic sheet. To evaluate the influence of the flow rate of water on root hair development, the water supply was controlled by a peristaltic pump (2232 MicroPerpex S, LKB BROMMA, Sweden) adjusted to provide a flow rate of $0.04,0.07,0.2,0.4,1.0$, or $4.0 \mathrm{ml} / \mathrm{min}$. For an even water distribution, the water was pumped onto a cheese cloth strip (6-layer, $1 \mathrm{~cm}$ wide) along the upper edge of the mat. To examine the effect of exogenous ethylene on root hair development in the mat system, ethephon (Fisher Scientific, Pittsburgh, PA) was added to the water supply at a concentration of $0.031 \mathrm{mM}$ at $24 \mathrm{hr}$ following seeding. After another $24 \mathrm{hr}$, the ethephon solution was replaced by a fresh preparation of the same concentration.

2. The mist growth system is described in Figure 1B. Two hundred seeds were germinated on $400 \mathrm{~cm}^{2}$ of paper towel spread over an aluminum screen 
slanted at approximately $4^{\circ}$ in a plastic chamber exposed to a flowing mist provided by an aeroponic system (NUTRI-MISTER ${ }^{\mathrm{TM}}$ 0100, Waterford Equipment Company, Big Flats, NY) with an ultrasonic probe. To examine the effect of mist flow on root hair development, the mist flow rate in the aeroponic system was set at 15,68 , or $136 \mathrm{l} / \mathrm{min}$. These settings influenced the relative amount of moisture produced, but not relative humidity, which was maintained at $100 \%$. To examine the effect of oxygen on root hair development, seedlings were exposed to one of four oxygen concentrations $\left(0.2,2.0,10.5\right.$, or $20.8 \% \mathrm{O}_{2}$ ). Compressed $\mathrm{O}_{2}, \mathrm{CO}_{2}$, and $\mathrm{N}_{2}$ (Airgas East, Inc., Ithaca, NY) were used to obtain gas mixtures containing $0.2,2.0,10.5$, or $20.8 \% \mathrm{O}_{2}$ plus $0.035 \% \mathrm{CO}_{2}$ in $\mathrm{N}_{2}$ by controlling flow rate using flow meters (Bel-Art Products, Pequannock, NJ). The gas mixture was utilized by the aeroponic system to keep the mist flowing. Controlled atmospheres were monitored every $12 \mathrm{hr}$ by gas chromatography (Fisher GAS PARTITIONER, model 1200, Fisher Scientific, Pittsburgh, PA) using a thermal conductivity detector and two different columns $(165 \times 3 \mathrm{~mm}$, packed with $80 / 100$ mesh Porapak Q; $279 \times 5 \mathrm{~mm}$, packed with $60 / 80$ mesh molecular sieve 13X). The oven temperature was $90^{\circ} \mathrm{C}$, and the injector temperature was $135^{\circ} \mathrm{C}$. The carrier gas was helium with a flow rate of $30 \mathrm{ml} / \mathrm{min}$. To examine the effect of $\mathrm{Ag}^{+}$(an inhibitor of ethylene action) on root hair development, water was replaced by silver thiosulphate (STS) solution for generating mist after $24 \mathrm{hr}$ of germination. STS solutions were prepared by mixing $\mathrm{AgNO}_{3}$ with $\mathrm{Na}_{2} \mathrm{~S}_{2} \mathrm{O}_{3}$ in a 1:4 (w/v) molar concentration ratio (Kamaluddin and Zwiazek, 2002).

Measurements of Root Hairs. After seed was germinated for $60 \mathrm{hr}, 10$ seedlings were randomly selected from each experimental run. A 1-cm root segment was excised from each seedling beginning at $0.5 \mathrm{~cm}$ behind the root tip. Root segments were fixed in 70\% ethanol, placed on microscope slides (Corning Incorporated, Corning, NY), and covered by a glass cover. Three digital images were taken for each root segment from the ends and the middle using an Olympus BX-50 light microscope equipped with Differential Interference Contrast optics (Olympus America Inc., Melville, NY), a high resolution PentaMax cooled CCD camera (Princeton Instruments, Trenton, NJ), and MetaMorph software package (Version 4.5r4, Universal Imaging Corporation, Downingtown, PA). Root hair length and number present in the middle region $(684 \mu \mathrm{m})$ along the root length in each digital image were determined using the ruler tool in the AlphaEase (v5.5) software (Alpha Innotech Corporation, San Leandro, CA).

Two independent experimental runs were performed for each treatment, with each run giving statistically similar results. For all experiments, the means of two independent runs were combined. Data presented are the mean values recorded from 20 seedlings ( $\pm 95 \%$ confidence interval). One-way ANOVA with a Tukey's post hoc test was performed to separate means. 
High Performance Liquid Chromatography (HPLC) Analysis. Root exudates were extracted as described by Czarnota et al. (2001). Briefly, $2 \mathrm{~g}$ samples of fresh roots were dipped in $100 \mathrm{ml}$ of methylene chloride (acidified with $0.25 \%$ glacial acetic acid) for $\sim 2 \mathrm{~min}$. After the roots were removed from the solvent, the extract was filtered through an Acrodisc ${ }^{\circledR}$ CR $25 \mathrm{~mm}$ syringe filter with a 0.2- $\mu \mathrm{m}$ PTFE membrane (Pall Corporation, Ann Arbor, MI). The filtrate was concentrated to $2 \mathrm{ml}$ with a rotoevaporator (Büchi ROTAVAPOR R-111, Brinkmann Instruments, Inc., Westbury, NY) at $40^{\circ} \mathrm{C}$. Concentrated root exudates were transferred to preweighed vials, and dried under $\mathrm{N}_{2}$ gas. Root exudates were reconstituted with methylene chloride (acidified with $0.25 \%$ glacial acetic acid) to a concentration of $1 \mathrm{mg}$ exudates/ml. HPLC analysis of root exudates was performed as described by Czarnota et al. (2001). Briefly, $15 \mu \mathrm{l}$ of root exudates $(1 \mathrm{mg} / \mathrm{ml}$ in methylene chloride acidified with $0.25 \%$ glacial acetic acid) were subjected to HPLC analysis (Waters 2695 Separations Module, Waters Corporation, Milford, MA) using a Waters NovaPak C18 column $(150 \times 3.9 \mathrm{~mm})$. The mobile phase was eluted at $2 \mathrm{ml} / \mathrm{min}$ according to the following program: $0-15 \mathrm{~min}, 45 \% \mathrm{~A}(2.5 \%$ acetic acid in water $)+55 \% \mathrm{~B}$ (acetonitrile); 15-22 min, linear gradient from 55 to $100 \% \mathrm{~B} ; 22-25 \mathrm{~min}, 100 \% \mathrm{~B}$; 25-26 min, linear gradient from 100 to $55 \% \mathrm{~B}$; and 26-30 min, 45\% A + 55\% B. The components of the root exudates were detected at $280 \mathrm{~nm}$ with a Waters 996 photodiode array detector (Waters Corporation, Milford, MA), and identified by using a purified sorghum root exudate sample of which several components were chemically characterized (Rimando et al., 1998; Czarnota et al., 2001).

\section{RESULTS}

Effect of Air/Water Flow on Root Hair Development. Variations in the rate of air flow from 15 to $136 \mathrm{l} / \mathrm{min}$ did not significantly influence root hair density and length when seedlings were produced in the mist system. In comparison, root hair density and length were affected by the variations in the flow rate of water from 0.00 to $4.00 \mathrm{ml} / \mathrm{min}$ in the mat growth system, with a larger effect on root hair density than on root hair length (Figure 2). In this system, water flow at $0.07 \mathrm{ml} / \mathrm{min}$ or higher resulted in significant reductions in root hair density and length, while primary root length was not significantly inhibited (data not shown). When water flow rate was $0.4 \mathrm{ml} / \mathrm{min}$ or higher, the roots produced in the mat system were predominantly hairless (Figures $2 \mathrm{~A}$ and $3 \mathrm{~F}$ ).

Effect of Hypoxic Condition on Root Hair Development. In the mist growth system, there was no significant difference in root hair density between hypoxic $\left(0.2-10.5 \% \mathrm{O}_{2}\right)$ and ambient oxygen conditions (20.8\%) (Figure 4A). Treatment with $2 \% \mathrm{O}_{2}$ significantly increased the root hair length as compared to the ambient oxygen concentration $\left(20.8 \% \mathrm{O}_{2}\right)$, while two other subambient oxygen concentrations $\left(0.2\right.$ and $\left.10.5 \% \mathrm{O}_{2}\right)$ did not result in significant differences in root 

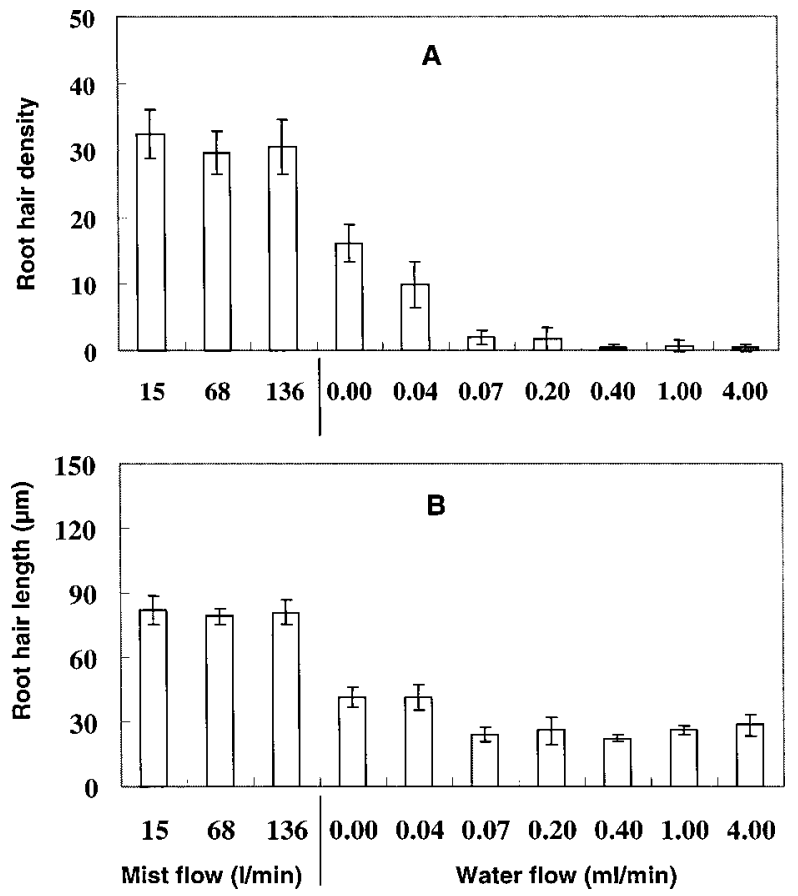

FIG. 2. Influence of water and air movement on root hair development. Sorghum seeds were germinated for $60 \mathrm{hr}$ using the mat or mist system as illustrated in Figure 1. Root hair density was measured as root hair number per $684 \mu \mathrm{m}$ root segment. Values shown represent the mean of 20 seedlings $\pm 95 \%$ confidence interval.

hair length (Figure 4B). The elongation of the primary roots was markedly inhibited by $0.2 \% \mathrm{O}_{2}$ compared to the standard air atmosphere (data not shown). These data indicate that reducing oxygen concentration in the mist system can not be utilized to efficiently inhibit root hair development, while maintaining normal root elongation.

Effect of $\mathrm{Ag}^{+}$on Root Hair Development. An application of $0.4 \mathrm{mM} \mathrm{Ag}{ }^{+}$ in the mist system significantly reduced root hair density and root hair length while primary root length was not significantly reduced as compared to the control (Figure 5). Increasing $\mathrm{Ag}^{+}$concentration resulted in further reduction in root hair density and root hair length, and $\mathrm{Ag}^{+}$generally had a larger effect on root hair length than on root hair density (Figure 5A and B). Root hair development was arrested at the swelling stage by a treatment with $2.00 \mathrm{mM} \mathrm{Ag}^{+}$(Figure 3D). However, under mist containing $2.00 \mathrm{mM} \mathrm{Ag}^{+}$, primary root growth was also markedly inhibited (Figure 5C). These data indicate that in comparison to modified $\mathrm{O}_{2}$ atmospheres, $\mathrm{Ag}^{+}$can efficiently inhibit root hair elongation, but can not cause 

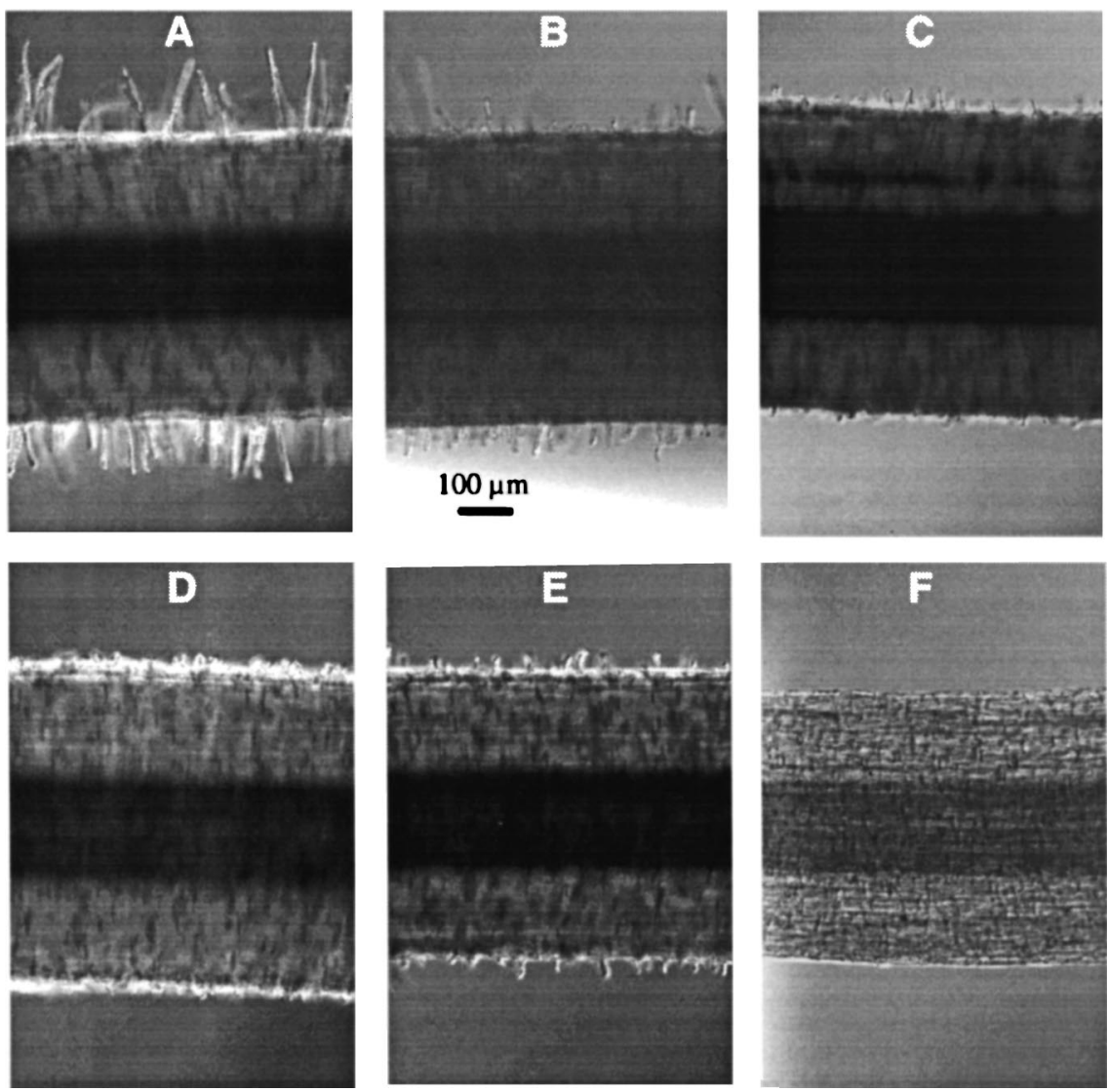

FIG. 3. Light micrographs of sorghum roots showing the effects of different environmental conditions. (A-D) Seed was germinated for $24 \mathrm{hr}$ under water mist, followed by $36 \mathrm{hr}$ under water mist containing $0,0.4,1.2$, and $2.0 \mathrm{mM} \mathrm{Ag}^{+}$, respectively. (E) Seed was germinated for $60 \mathrm{hr}$ in the mat system with water movement at $1.0 \mathrm{ml} / \mathrm{min}$. Ethephon was added to the water supply at $0.031 \mathrm{mM} 24 \mathrm{hr}$ following seeding. After another $24 \mathrm{hr}$, the ethephon solution was replaced by a fresh preparation of the same concentration. (F) Seed was germinated for $60 \mathrm{hr}$ in the mat system with water movement at $\geq 0.4 \mathrm{ml} / \mathrm{min}$.

complete inhibition of root hair formation even when the $\mathrm{Ag}^{+}$concentration is increased to a level inhibitory to primary root growth. Therefore, $\mathrm{Ag}^{+}$can not be utilized to efficiently inhibit root hair initiation, while maintaining normal root elongation. It is reasonable to suggest that ethylene promotes root hair development in the seedlings of sorghum SX17, but is not the only positive regulator of this phenomenon. 

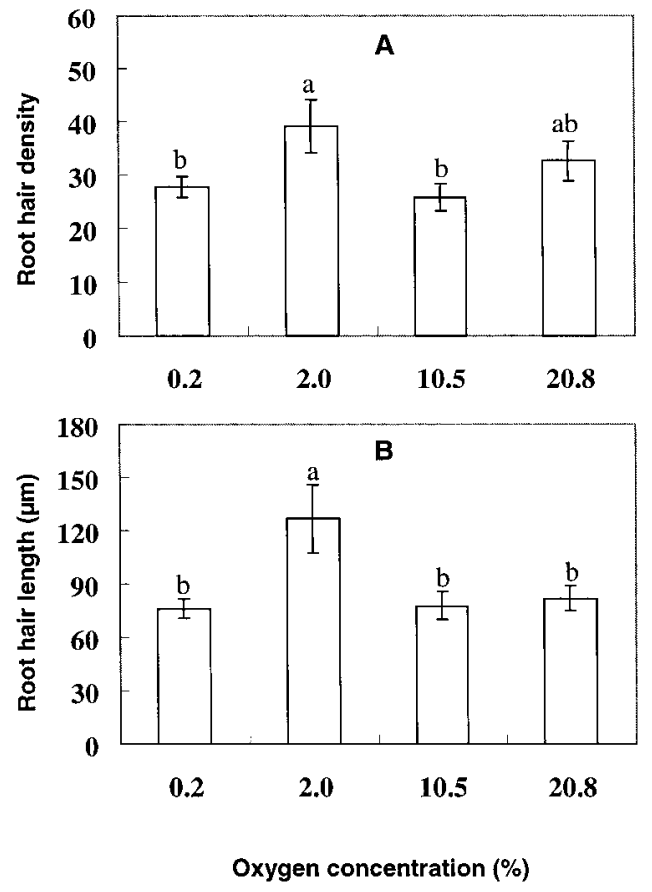

FIG. 4. Influence of hypoxic condition on root hair development in the mist system. Sorghum seeds were germinated in a standard air atmosphere $\left(20.8 \% \mathrm{O}_{2}\right)$ for $24 \mathrm{hr}$, followed by $36 \mathrm{hr}$ of the indicated modified oxygen treatment. Root hair density was measured as root hair number per $684 \mu \mathrm{m}$ root segment. Values shown represent the mean of 20 seedlings $\pm 95 \%$ confidence interval. Different letters are used to indicate means that differ significantly $(P<0.05)$.

Effect of Ethephon on Root Hair Development. An application of ethephon at $0.031 \mathrm{mM}$ to the water supply, flowing at $1 \mathrm{ml} / \mathrm{min}$, significantly increased root hair density and root hair length as compared to the treatment with no ethephon added. There was no significant difference in root hair density and length between the treatment with no water flow and the treatment with a $0.031 \mathrm{mM}$ ethephon solution moving at $1 \mathrm{ml} / \mathrm{min}$ (Figure 6). These data indicate that ethephon can reverse the inhibition of root hair development by water movement in the mat system.

Root Exudation. Sorghum root exudates were collected from seedlings grown in the mist system. The root exudate contained at least five related compounds including sorgoleone, as identified using a purified sorghum root exudate sample in which several components were chemically characterized (Rimando et al., 1998; Czarnota, 2001). In comparison, the roots of seedlings grown under the mat system 

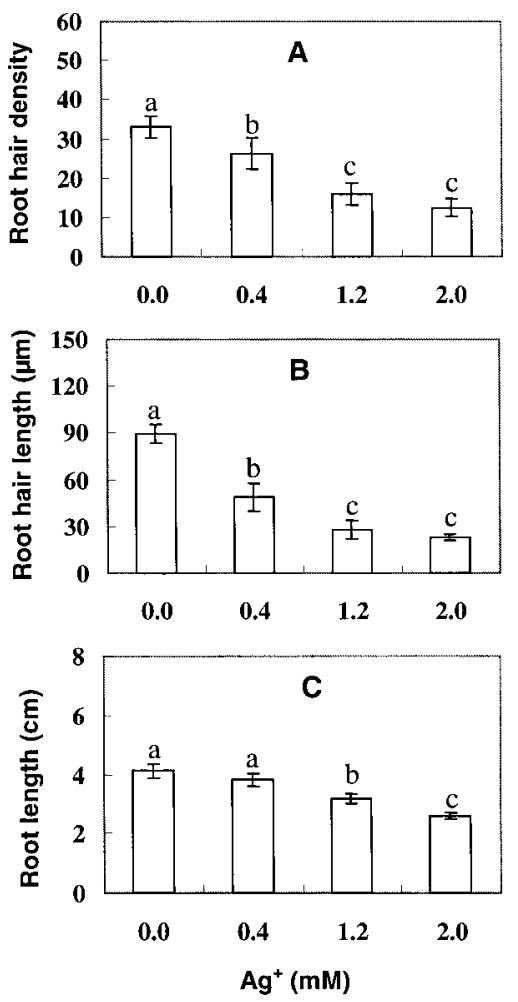

FIG. 5. Influence of $\mathrm{Ag}^{+}$on root hair development in the mist system. Sorghum seeds were germinated for $24 \mathrm{hr}$ under mist, followed by $36 \mathrm{hr}$ under water mist supplemented with $\mathrm{Ag}^{+}(0,0.4,1.2$, or $2.0 \mathrm{mM})$. Root hair density was measured as root hair number per $684 \mu \mathrm{m}$ root segment. Values shown represent the mean of 20 seedlings $\pm 95 \%$ confidence interval. Different letters are used to indicate means that differ significantly $(P<0.05)$.

maintaining a high water flow rate of $15 \mathrm{ml} / \mathrm{min}$ did not produce any sorgoleone in the root extracts (Figure 7).

\section{DISCUSSION}

Recent work in our laboratory has identified the site of sorgoleone synthesis as the sorghum root hairs (Czarnota et al., 2001). Successful manipulation of root hair production can facilitate analysis of gene expression associated with sorgoleone production in sorghum root hairs. We have established two growth systems that produce significant differences in root hair development, while minimizing 

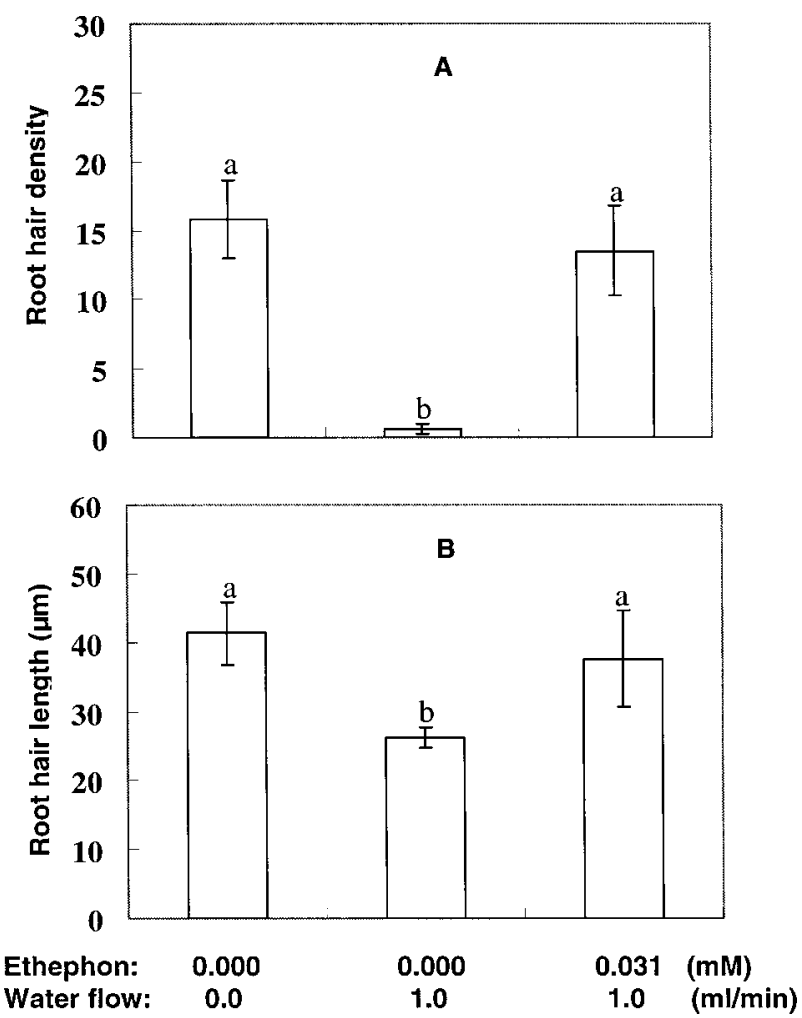

FIG. 6. Effect of ethephon on root hair development in the mat system in relation to water flow rate. Root hair density was measured as root hair number per $684 \mu \mathrm{m}$ root segment. Values shown represent the mean of 20 seedlings $\pm 95 \%$ confidence interval. Different letters are used to indicate means that differ significantly $(P<0.05)$.

differences in primary root growth. Sorghum seedlings grown in our mist system with air flow at $15 \mathrm{l} / \mathrm{min}$ produced abundant root hairs exuding sorgoleone, whereas those grown in our mat system with water flow at $\geq 0.4 \mathrm{ml} / \mathrm{min}$ produced predominantly hairless roots which subsequently did not exude sorgoleone (Figures 2 and 7).

As compared with ecotype Columbia, the ethylene-overproducing Arabidopsis mutants eto1-1, eto2, and eto3 exhibited increased numbers and lengths of root hairs. The ethylene-insensitive mutants etr1-1, ein2-1, and ein3-1 exhibited decreased root hair lengths, but normal root hair densities (Wubben et al., 2001). These findings support the assumption that ethylene promotes root hair development, but is not the only positive regulator of this phenomenon. This assumption is also supported by our experiments. For example, applying the ethylene inhibitor 


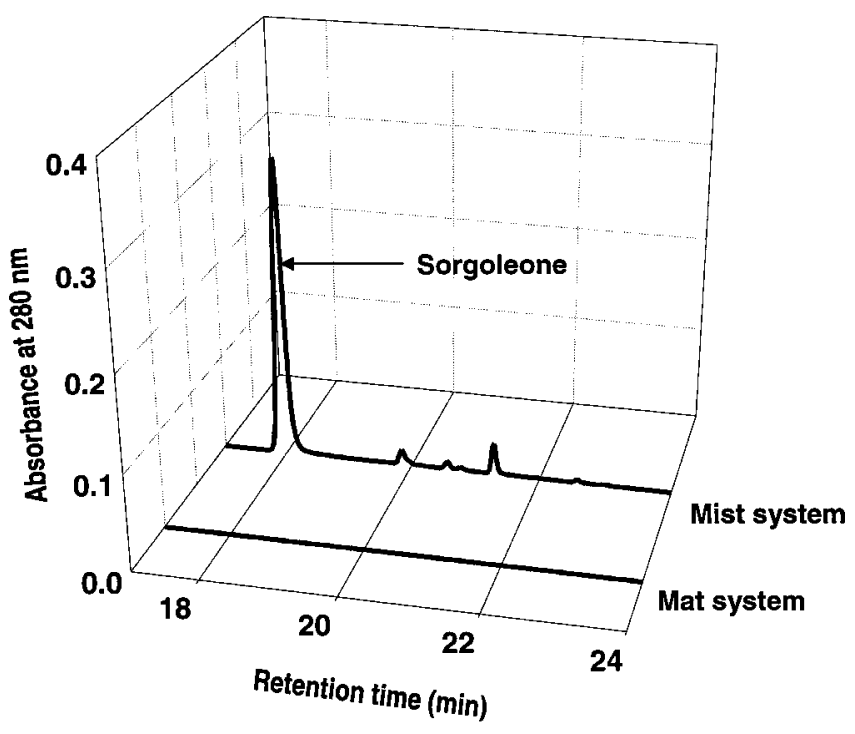

FIG. 7. HPLC profile of root exudates produced by the roots of sorghum SX17 seedlings. The seeds were germinated for $60 \mathrm{hr}$ using the mat system with water flow at $15 \mathrm{ml} / \mathrm{min}$ and mist system with air flow at 15 1/min as illustrated in Figure 1.

$\mathrm{Ag}^{+}$to sorghum seedlings grown in the mist system resulted in significant inhibition of root hair initiation and elongation. However, even when $\mathrm{Ag}^{+}$concentration was increased to a level that was inhibitory to primary root growth, root hair initiation was not completely suppressed (Figures 3D and 5). Recently, it was reported that endogenous auxin plays a complementary role for root hair development in the absence of an ethylene response in Arabidopsis (Rahman et al., 2002).

The final step in the ethylene biosynthetic pathway (the conversion of ACC to ethylene) requires the presence of oxygen. It was recently reported that ethylene was not detected in Arabidopsis silique tissue produced under subambient oxygen (2.5 or 5.5\%) conditions (Ramonell et al., 2002). However, in our studies, the reduction of $\mathrm{O}_{2}$ supply in the mist system did not inhibit root hair growth. In contrast, a moderate hypoxic condition $\left(2.0 \% \mathrm{O}_{2}\right)$ enhanced root hair growth in comparison to standard atmosphere conditions (Figure 4). Brailsford et al. (1993) also reported that 3 or $5 \% \mathrm{O}_{2}$ increased ethylene production in the primary roots of 72-hr-old seedlings of Z. mays cv. LG11 as compared to 1.0, 12.5, or $20.8 \% \mathrm{O}_{2}$, and no ethylene production was detected in the complete absence of oxygen. We hypothesize that in our studies, $2 \% \mathrm{O}_{2}$ resulted in an enhanced ethylene production in sorghum roots as compared to $0.2,10.5$, or $20.8 \% \mathrm{O}_{2}$ and, thus, increased root hair length. 
Root hair initiation and elongation of sorghum seedlings grown in the mat system were significantly inhibited as compared to those grown in the mist system (Figure 2). In the rhizosphere, an increase in gas exchange at the root surfaces accelerates removal of ethylene and consequently limits its function in root hair formation (Michael, 2001). Similarly, it can be expected that water running over the roots can accelerate the movement of endogenous ethylene away from the root surfaces, thus inhibiting root hair formation. This speculation is supported by our experiments with the ethylene-releasing agent ethephon. Applying ethephon at $0.031 \mathrm{mM}(4.5 \mathrm{ppm})$ reversed the inhibition of root hair development by water flow at $1 \mathrm{ml} / \mathrm{min}$ in the mat system (Figures 3E, F, and 6).

The presence of living root hairs clearly influences the amount of sorgoleone that is exuded by living sorghum roots. Our studies indicate that ethylene influences root hair formation and subsequently sorgoleone production. In soil, ethylene accumulation is influenced by various factors such as microorganisms, humus, total nitrogen, water tensions, and oxygen supply (Zechmeister-Boltenstern and Nikodim, 1999). Therefore, it is possible that in field practice we can manipulate these soil factors to optimize ethylene concentration in the rhizosphere and consequently enhance root hair development and sorgoleone production in sorghum cover crops in an effort to develop crop-based weed management system. For analysis of differential gene expression associated with root hair development and sorgoleone production in sorghum, our mist system with air flow at $15 \mathrm{l} / \mathrm{min}$ can be used to produce sorghum roots with abundant roots hairs exuding sorgoleone, while our mat system with water movement at $\geq 0.4 \mathrm{ml} / \mathrm{min}$ can be used to produce predominantly hairless roots which do not exude sorgoleone.

Acknowledgments-The authors thank Roselee Harmon for technical assistance with HPLC analysis and root hair-counting.

\section{REFERENCES}

Brailsford, R. W., VoeseneK, L., Blom, C., SMith, A. R., Hall, M. A., and JaCKSON, M. B. 1993. Enhanced ethylene production by primary roots of Zea mays $\mathrm{L}$ in response to sub-ambient partial pressures of oxygen. Plant Cell Environ. 16:1071-1080.

CAO, X. F., LINSTEAD, P., BERGER, F., KIEBER, J., and DOLAN, L. 1999. Differential ethylene sensitivity of epidermal cells is involved in the establishment of cell pattern in the Arabidopsis root. Physiol. Plant. 106:311-317.

Chang, M., Netzly, D. H., ButLer, L. G., and LynN, D. G. 1986. Chemical regulation of distanceCharacterization of the 1st natural host germination stimulant for Striga asiatica. J. Am. Chem. Soc. 108:7858-7860.

Cormack, R. G. H. 1949. The development of root hairs in angiosperms. Bot. Rev. 15:583612.

Czarnota, M. A. 2001. Sorghum (Sorghum spp.) Root Exudates: Production, Localization, Chemical Composition, and Mode of Action. PhD Dissertation. Cornell University, Ithaca, NY. 
Czarnota, M. A., Paul, R. N., Dayan, F. E., Nimbal, C. I., and Weston, L. A. 2001. Mode of action, localization of production, chemical nature, and activity of sorgoleone: A potent PSII inhibitor in Sorghum spp. root exudates. Weed Technol. 15:813-825.

Dolan, L. 2001. The role of ethylene in root hair growth in Arabidopsis. J. Plant Nutr. Soil Sci. 164:141-145.

Duke, S. O., Scheffler, B. E., DAyan, F. E., Weston, L. A., and OtA, E. 2001. Strategies for using transgenes to produce allelopathic crops. Weed Technol. 15:826-834.

EINHELLIG, F. A. 1995. Mechanism of action of allelochemicals in allelopathy, pp. 96-116, in Allelopathy. American Chemical Society, Washington.

Einhellig, F. A., Rasmussen, J. A., HeJl, A. M., and SouZA, I. F. 1993. Effects of root exudate sorgoleone on photosynthesis. J. Chem. Ecol. 19:369-375.

EINHELlig, F. A. and SouZA, I. F. 1992. Phytotoxicity of sorgoleone found in grain sorghum root exudates. J. Chem. Ecol. 18:1-11.

Fan, T. W. M., Lane, A. N., Shenker, M., Bartley, J. P., Crowley, D., and Higashi, R. M. 2001. Comprehensive chemical profiling of gramineous plant root exudates using high-resolution NMR and MS. Phytochemistry 57:209-221.

Gonzalez, V. M., Kazimir, J., Nimbal, C., Weston, L. A., and Cheniae, G. M. 1997. Inhibition of a photosystem II electron transfer reaction by the natural product sorgoleone. J. Agric. Food Chem. 45:1415-1421.

GRESSEL, J. 2000. Molecular biology of weed control. Transgenic Res. 9:355-382.

Grierson, C. S., PARKer, J. S., and KeMP, A. C. 2001. Arabidopsis genes with roles in root hair development. J. Plant Nutr. Soil Sci. 164:131-140.

Heidstra, R., Yang, W. C., Yalcin, Y., Peck, S., Emons, A. M., VAnKammen, A., and Bisseling, T. 1997. Ethylene provides positional information on cortical cell division but is not involved in Nod factor-induced root hair tip growth in Rhizobium legume interaction. Development 124:17811787.

INDERJIT and WeStON, L. A. 2003. Root exudates: An overview, in H. de Kroon and E. J. W. Visser (eds.). Root Ecology. Springer-Verlag, Heidelberg, Germany.

KAMALUDDIN, M. and ZWIAZEK, J. J. 2002. Ethylene enhances water transport in hypoxic aspen. Plant Physiol. 128:962-969.

Meazza, G., Scheffler, B. E., Tellez, M. R., Rimando, A. M., Romagni, J. G., Duke, S. O., NanayakKara, D., Khan, I. A., Abourashed, E. A., and Dayan, F. E. 2002. The inhibitory activity of natural products on plant p- hydroxyphenylpyruvate dioxygenase. Phytochemistry 60:281-288.

Michael, G. 2001. The control of root hair formation: Suggested mechanisms. J. Plant Nutr. Soil Sci. 164:111-119.

NetZly, D. H. and ButLER, L. G. 1986. Roots of sorghum exude hydrophobic droplets containing biologically active components. Crop Sci. 26:775-778.

Nimbal, C. I., Pedersen, J. F., Yerkes, C. N., Weston, L. A., and Weller, S. C. 1996. Phytotoxicity and distribution of sorgoleone in grain sorghum germplasm. J. Agric. Food Chem. 44:13431347.

Parker, J. S., CaVell, A. C., Dolan, L., RoberTs, K., and Grierson, C. S. 2000. Genetic interactions during root hair morphogenesis in Arabidopsis. Plant Cell 12:1961-1974.

Pemberton, L. M. S., TSAi, S. L., Lovell, P. H., and Harris, P. J. 2001. Epidermal patterning in seedling roots of eudicotyledons. Ann. Bot. 87:649-654.

Pereira-NetTo, A. B. 2001. Effect of inhibitors of ethylene biosynthesis and signal transduction pathway on the multiplication of in vitro grown Hancornia speciosa. Plant Cell Tissue Organ Cult. 66:1-7.

Peterson, R. L. and FARQUHAR, M. L. 1996. Roots hairs: Specialized tubular cells extending root surfaces. Bot. Rev. 62:1-40. 
Rahman, A., Hosokawa, S., Oono, Y., Amakawa, T., Goto, N., and Tsurumi, S. 2002. Auxin and ethylene response interactions during Arabidopsis root hair development dissected by auxin influx modulators. Plant Physiol. 130:1908-1917.

Ramonell, K. M., MCClure, G., and Musgrave, M. E. 2002. Oxygen control of ethylene biosynthesis during seed development in Arabidopsis thaliana (L.) Heynh. Plant Cell Environ. 25:793-801.

Rasmussen, J. A., Hejl, A. M., Einhellig, F. A., and Thomas, J. A. 1992. Sorgoleone from root exudate inhibits mitochondrial functions. J. Chem. Ecol. 18:197-207.

RIDGE, R. W. 1995. Recent developments in the cell and molecular biology of root hairs. J. Plant Res. 108:399-405.

Rimando, A. M., Dayan, F. E., Czarnota, M. A., Weston, L. A., and Duke, S. O. 1998. A new photosystem II electron transfer inhibitor from Sorghum bicolor. J. Nat. Prod. 61:927-930.

RoBERTS, D. G. 1993. Root-hair structure and development in the seagrass Halophila ovalis (R. Br.) Hook. f. Aust. J. Mar. Fresh. Res. 44:85-100.

Row, H. C. and REEDER, J. R. 1957. Root-hair development as evidence of relationships among genera of Gramineae. Am. J. Bot. 44:596-601.

RyAn, E., SteER, M., and Dolan, L. 2001. Cell biology and genetics of root hair formation in Arabidopsis thaliana. Protoplasma 215:140-149.

WESTON, L. A. 1996. Utilization of allelopathy for weed management in agroecosystems. Agron. J. 88:860-866.

Wubben, M. J. E., Su, H., Rodermel, S. R., and Baum, T. J. 2001. Susceptibility to the sugar beet cyst nematode is modulated by ethylene signal transduction in Arabidopsis thaliana. Mol. Plant-Microbe Interact. 14:1206-1212.

ZECHMEISTER-BOLTENSTERN, S. and NIKODIM, L. 1999. Effect of water tension on ethylene production and consumption in montane and lowland soils in Austria. Eur. J. Soil Sci. 50:425-432. 